\title{
INSTRUCTORS AND STUDENTS ON THE SAME PAGE: USABILITY OF INSTRUCTOR LOADED RESOURCES IN LMS SITES
}

\author{
Geraldine Torrisi-Steele, Tessa Atkinson \\ Griffith University (AUSTRALIA)
}

\begin{abstract}
Usability or 'ease of use' is a significant determinant of the user's experience of an interactive system. The vast majority of university students worldwide use learning management systems (LMS) to access and interact with the course materials which instructors have loaded into the LMS. Students' experience of their courses colors their experience of program and even of the institution. Providing a positive student experience is important to learning outcomes and to institutional competitiveness. Usability of learning resources also influences student motivation, engagement and learning. Ensuring usability of an LMS course built by instructors is important. However, a review of literature shows that the usability of instructor loaded resources in LMS is under-explored.

The authors undertake a preliminary investigation of the usability of LMS instructor loaded resources. Adopting Jakob Nielsen's ideas of mental models in usability, the authors conducted semi-structured interviews with five teaching academics and four students. The results show some mismatches between student and instructor mental models, reveal some students' expectations of course sites, justify the need for participatory approaches to LMS course design, and provide impetus for further studies.
\end{abstract}

Keywords: usability, higher education, instructional design, LMS, instructor-loaded resources, mental models, $\mathrm{HCl}$, course design, online learning, e-learning.

\section{INTRODUCTION}

Commonly defined as 'ease of use' or 'the amount of cognitive effort a user of an interactive system must expend to achieve their objectives', usability is integral to the user experience [1]. Students' experience of online learning materials influences the student experience of a course, and cumulatively influences the students' overall experience of program and even of the institution. Providing a positive student experience influences learning outcomes and institutional competitiveness. There is some evidence that when online learning materials are highly usable, students' "extraneous cognitive load is reduced" and the potential for effective learning is maximized [2]. Usability also taps into the affective dimension of learning and potentially influences the motivation of students to engage with the learning environment [2] [3] [4]. Usability of the online learning environment is imperative to student and institutional success.

University students usually access online learning via courses held within a Learning Management System (LMS). This is the case in both fully online modes, and in blended modes with varying degrees of face to face classes. LMS courses consist of two layers: the LMS shell, and the course materials uploaded. The LMS shell contains features such as announcements (noticeboards), discussion boards, wikis, quizzes and other functionalities, which are native or integrated components of the LMS. The features of the LMS shell are institutionally selected and oftentimes formatted according to the institutions' guidelines for practice. The LMS shell and platform itself constrains the overall design of the courses since it constrains functionality (what can/can't be done) and influences the architecture and appearance of the user interface. Hence, the usability of the learning materials can be considered the resultant of the usability of the LMS shell combined with the usability of uploaded learning resources. The authors acknowledge that the learning design of the individual learning resources also impact on overall usability of the LMS course. However, for the present paper, the design of the individual learning resources is beyond scope. Learning design is complex and requires much discussion and analysis of learning and teaching principles and theories. Furthermore, the learning design of individual learning resources and the learning environments are relatively well-explored in literature whereas usability is not.

Usually, it is the course instructors who design and develop the learning resources (lecture content in the form of slides, documents, assessment items etc.) which are uploaded to the course site within the institutionally adopted LMS. In uploading resources to the LMS, course instructors determine 
which resources they will upload, how those resources will be organized and categorized, the navigation pathways among resources, and which functionalities from the LMS shell (e.g. announcements, social media tools etc.) will be made available to students. Whether instructors are aware of it or not, the role of the course instructor extends beyond 'teaching' to that of a user interface and interaction designer.

The usability of various LMS and of e-learning as delivered via websites and mobile apps is explored in literature [5] [4]. But the usability of instructor-loaded resources within an LMS is rarely explored [6] [3], yet, it is one of the most common means of online course creation in higher education. To verify this view, we conducted a search of multi-disciplinary database, ProQuest Central, using keywords (("online learning" OR "e-learning") AND "usability), (("online learning" OR "e-learning") AND "usability" AND "design")). The search was limited to peer-reviewed journals and academic conferences, with full text access. The initial search included papers from the year 2000, about the time that the internet and online access became readily accessible to the broader population. However, it was noted that the density of publications was significantly greater in the last decade. The search was subsequently limited to the years 2010-2020, and results were sorted by relevance. Taking the 100 most relevant papers from the search we noted that 20 of the 100 papers were focused on usability. Among these papers, usability was discussed/investigate in relation to evaluation and user satisfaction of: a) specific digital tools such as e-books or mobile apps (six papers); b) websites for e-learning (eight papers); and c) the LMS shell and functionality (six papers). The majority literature surrounding online learning and teaching resources, related prominently underpinning discipline content and requirements, and instructional strategies such as active learning, and usability was mentioned in passing.

Fig. 1 captures the principal concept associations with the concept of usability in the full text of the 100 selected papers. The concept associations in Fig. 1 show usability as a parameter for evaluation of websites and systems, as is linked to quality and user satisfaction but not well linked directly to learning of concepts or content. Usability of instructor loaded teaching and learning resources did not feature.

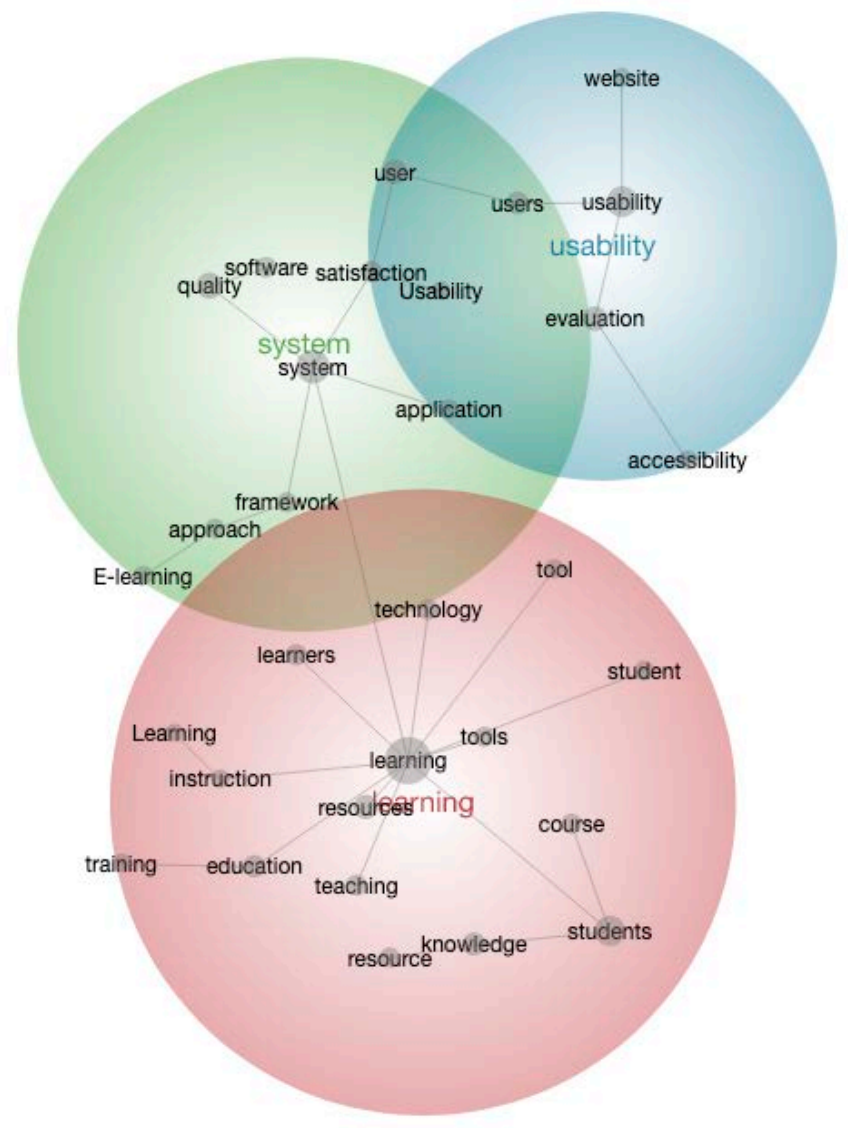

Figure 1. Key Concept associations with usability as generated for the full text of 100 papers relevant to online learning and usability 
Usability and interface design tend to be under-emphasized in the field of instructional design overall, but particularly so in the case of instructor loaded resources within an LMS [4]. Hence, the overarching goal of the present paper is to bring usability to the fore of instructors' thinking as they select, design and organize the resources they load within their LMS course sites. The authors hope to stimulate rich discussion around this issue.

The frame of mental models is adopted in the present paper. Mental models are the beliefs held by individuals about the purpose, structure and function of a system. A mental model is a deeply individual understanding of how something works and what can be done with it. The result of experiences, accumulated knowledge, beliefs, values and attitudes, mental models evolve over time [7]. The usability of an interactive systems results when the designers' mental model matches the mental model of the user [1]. Mental models are central to the concept of usability because the individual conceptualization of the interactive system determines its manner of use. Insights into the usability of instructor loaded resources can therefore be gained by exploring mental models and asking:

What are the mental models of the instructors in relation to how students organize and make use of the LMS course site?

What are the students' mental models of what the LMS course site enables them/should enable them to do? How and for what purposes are students using the LMS course sites?

In the present paper the authors report on a small preliminary investigation to gain some insight into both instructor and student mental models of LMS course sites as built by instructors. The insights gained from semi-structured interviews with students and instructors substantiate the claim that there are differences between student and instructor mental models of the LMS course site. The differences have the potential to impact on student satisfaction and engagement with the course. The insights gained from the reported investigation are disseminated to instructors as a starting point for informing the decisions they make in selecting and organizing the resources they load into LMS course sites. Results highlight the need to actively seek student feedback on the design of course sites within the LMS. The results serve as a launching point for encouraging instructors to engage in 1) participatory approaches to course site design and 2) undertake practice research into effective design of LMS course sites.

\section{METHODOLOGY}

To gain preliminary insights into the mental models of instructors and students with respect to the structure and organization of instructor loaded resources in an LMS (Blackboard), five teaching academics and four students from various disciplines, from the authors' home institution were interviewed. The semi-structured interviews were 15-20 minutes in duration. The courses are being offered in blended mode.

Key questions for the academics included:

- What do you take into consideration when you are loading content onto the LMS? What factors inform your decisions about what you put into and how you structure your course site?

- Give a story to illustrate how you believe students use your course site?

Key questions asked of the students included:

- Tell me about your experience of using L@G (institutional LMS for Griffith University)?

- How do you use L@G course site? What do you like/not like? Why?

A theme analysis of responses from interviews was conducted.

\section{RESULTS}

The core aspects of the mental model of the LMS course sites from student and instructor perspective are summarised in Table 1. Three dimensions of student and instructor mental models of LMS course sites emerged from the interview data: purpose of the LMS course site, navigation or wayfinding and functionality. 
Table 1. Aspects of mental model of the LMS course sites from student and instructor perspective

\begin{tabular}{c|l|l}
\hline \multicolumn{1}{c|}{ Aspect } & \multicolumn{1}{|c}{ Students' mental model } & \multicolumn{1}{c}{ Instructors' mental model } \\
\hline Purpose & $\begin{array}{l}\text { At course beginning, use it as a course orientation. } \\
\text { Access course content, assessment and other } \\
\text { resources. } \\
\text { Helps learning not just access content. } \\
\text { A way for lecturer and students to keep in touch } \\
\text { and keep communication channels open. }\end{array}$ & $\begin{array}{l}\text { Make sure students have everything they } \\
\text { need. What they need to learn, how to } \\
\text { learn and how they will be assessed. } \\
\text { Provide content and a schedule. } \\
\text { Provide only what they need otherwise it } \\
\text { becomes 'messy'; Keep it simple. } \\
\text { Provide only what is relevant and that they } \\
\text { need, everything else is "just noise" }\end{array}$ \\
\hline Wavigation/ & $\begin{array}{l}\text { Structure it so it "makes sense". } \\
\text { "Sometimes the interface is 'non-sensical'. } \\
\text { Use categories and "headings that are descriptive. } \\
\text { For example: 'assessment information' can mean } \\
\text { anything" } \\
\text { "Folder pathways [and subfolders' are weird" }\end{array}$ & $\begin{array}{l}\text { Make it easy to find things. } \\
\text { "Organise the content for them" }\end{array}$ \\
\hline Functionality & $\begin{array}{l}\text { Provide additional learning resources and know } \\
\text { what I have to learn or do and what is optional. } \\
\text { Know how particular content is used e.g. } \\
\text { compulsory, extension, just for interest } \\
\text { Provide other resources and guidance to help me } \\
\text { learn. } \\
\text { Helps me to 'stay on task' through continuity of } \\
\text { communication with lecturer. More than just } \\
\text { knowing what is going on. } \\
\text { Works on mobile devices such as smart phone. }\end{array}$ & $\begin{array}{l}\text { "Lectures, workshops, being able to check } \\
\text { marks and announcement is all the } \\
\text { functionality they need." } \\
\text { noticeboard the reminders for upcoming } \\
\text { lectures and assessment. }\end{array}$ \\
\hline \hline
\end{tabular}

A consideration of themes presented in Table 1, reveals that the instructor mental model of LMS course purpose is dominated by content delivery and access to information. In contrast, the student mental model of the purpose of the LMS course encompasses ideas beyond access to content and information. Alongside content delivery, students indicated they expect to find course sites provide additional resources e.g. to external sites, books etc to support their learning and, importantly, provide guidance as to the how to use those resources and make explicit the importance and purpose of resources 'compulsory, extended, for interest'. One particularly interesting point is made by students regarding the role of the course site to 'keep students on task', rather than only communicating what was happening in the course in regard to class locations, upcoming assessments etc.

Providing all that students needed and making it easy for students to find content is a priority for the course site according to the mental models held by instructors. One instructor noted that to decide on structure and headings, he tries to adopt a student, while at the same time giving due consideration to the relationships of concepts within the content. Despite this, finding content, information about assessment etc. is seemingly a major pain point for students.

During interviews with students, exploration of navigation lead to discussion around consistency of presentation and organisation across multiple courses. Interestingly, students acknowledged the differences among courses will necessarily influence LMS course site. Students were very forgiving of variation in instructor loaded resource presentation across courses but expressed the need to have consistency in terminology and layout within the course itself. Disciplinary and course differences were present in the mental model of students and manifested as tolerance or even expectation of finding differences among courses with respect to terminology, information architecture and appearance.

\subsection{Recommendations and further research}

The insights from the investigation were shared with teaching academics in the authors department at their home institution and also shared here. Although context of the participants was the Blackboard LMS (L@G) used within Griffith university, the recommendations relate to common elements found across different LMS and are hence valuable outside of the authors' institutional context. 
Recalling Norman's [1] assertion that usability of interactive systems is optimal when the mental model of the system held by designers matches the mental model of the users, the following recommendations are made to bring the instructor mental models closer to that of the students in relation to LMS course sites:

\subsubsection{Orientation to courses}

Prior to the course beginning consider what course materials and information should be uploaded to assist students orientate themselves in the course: Some information to be uploaded will include

- Staff contact information

- Upload, as a minimum, essential course content and provide at the very least, enough files and categories to convey to students with an "architecture of the course". Consider using the announcements page to welcome students and to provide a synopsis of the course along with an indication of timelines for activities and assessment.

\subsubsection{Navigation, wayfinding, and communication}

As a result of the interviews it was found that there's two types of structures that students might look for:

- content categories: course lectures, lecture capture, workshops, assessment

- 'guidance' categories: what is essential? What is optional (and in what way): What is interesting? What is extended information? What tasks should I do first? How should I pace myself?

The need for categorization "that makes sense" is important. From the interviews it seems that sense making is even more important than simply consistency of presentation. One student points out that the way the site is laid out will be different for different 'types' of courses.

There are two layers of consistency which emerge from the interviews

- consistency elements that are common to all courses in the university (e.g. staff information, course profile)

- consistency across courses of the 'same type'. For further investigation explore more deeply what makes a course of the same type. Is it disciplinary difference? Is it teaching approach? Is it some interplay of both these factors? Is it possible to create models for the architecture and function instructor loaded resources for different course types?

The announcements or noticeboard LMS page isn't just about what's happening but plays a role in guiding students as to what they need to do and where they are at. One student commented that communication is important if students are to 'stay on task'. The use of the announcements page for this purpose appears under-explored. Particularly for courses fully online, the noticeboard or announcement can serve as a running commentary which targets and scaffolds critical thinking, reflection and academic self-regulation. Consider exploring how the announcements/Noticeboard (or email) can be used as tool to guide and scaffold higher order thinking skills.

The instructor loaded resources include resources outside of those provided by the instructor. The instructor loaded resources direct students to external learning resources which can support learning. A strong theme emerged that students are looking to the $L @ G$ site not just as content delivery but also as a resource in itself to help progress and guide their learning.

\section{CONCLUSION}

The vast majority of university students worldwide engage with course materials loaded by instructors into course sites on the institutional LMS. Usability is essential to students' positive experience and engagement with learning materials and can influence motivation and learning. While usability is somewhat explored in relation to e-learning materials, websites and apps, there is little if any attention to the usability of the course sites created by instructors as they load learning materials onto course sites within an LMS.

The results of the preliminary investigation reported in the present paper, clearly show a mismatch between the mental model of the participant students and instructors when it comes to LMS course 
sites. Among those interviewed, it is apparent that instructors consider the primary purpose of the LMS course site for providing needed content and information, while students conceive of the LMS site as having purpose beyond content and information provision, to scaffolding and learning activity, and as a channel for the communication needed to 'keep students on task'. The need for instructors to seek feedback of students and to adopt a participatory approach to the design of LMS course sites is salient.

The investigation reported here is small and intended to serve primarily as stimulus for further thought and investigation. There is obvious need for further investigation, in different contexts, for larger scale studies to uncover in greater depth of detail the instructor and student mental models of LMS course sites, and to investigate more thoroughly usability of LMS course sites. As we write this paper, the COVID-19 pandemic has forced a leap into fully online learning, giving some urgency to the need to nurture among instructors not an 'uploading resources' mindset, but a mindset of usability, usercentredness and participatory design; seeing their role as teacher, interface and interaction designer blended into one.

\section{ACKNOWLEDGEMENTS}

With many thanks to our colleagues and fellow students who willingly gave their time to provide their valuable views.

\section{REFERENCES}

[1] D. A. Norman, "Some observations on Mental Models.," in Mental Models., Lawrence Erlbaum Associates, 1983, pp. 7-14.

[2] J. Gray and M. DiLoreto, "The effects of student engagement, student satisfaction, and perceived learning in online leanring environments," NCPEA International Journal of Educational Leadership Preparation, vol. 11, no. 1, 2016.

[3] P. Zaharias, "Usability in the context of e-learning: A framework augmenting 'traditional usability constructs with instructional design and motivation to learn.," International Journal of Technology and Human Interaction, vol. 5, no. 4, pp. 38-61, 2009.

[4] M. R. Davids, M. L. Halperin and U. M. Chikte, "Optimising cognitive load and usability to improve the impact of e-learning in medical education," AJHPE, vol. 7, no. 2, pp. 147-152, 2015.

[5] U. T. Alturki, A. Aldraiweesh and Kinshuck, "Evaluating The UsabilityAnd Accessibility Of LMS“Blackboard"At King Saud University," Contemporary Issues in Education Research, vol. 9, no. 1, pp. 33-44, First Quarter 2016.

[6] S. Thuseethan, S. Achcuthan and S. Kuhanesan, "Usability Evaluation of Learning Management Systems in Sri Lankan Universities," Global Journal of Computer Science and Technology: C Software and Data Engineering, vol. 15, no. 1, 2015.

[7] B. Xie, J. Zhou and H. Wang, "How Influential Are Mental Models on Interaction Performance? Exploring the Gap between Users' and Designers' Mental Models through a New Quantitative Method," Advances in Human-Computer Interaction, no. https://doi.org/10.1155/2017/3683546, 2017.

[8] L. Hasan, "The usefulness and usability of Moodle LMS as employed by Zarqa University in Jordan," Journal of Informaiton Systems and Technology Management, vol. 16, p. online, 2019.

[9] M. Eltahir, S. Al-Qatawneh, N. Al-Ramahi and N. Alsalhi, "THE PERSPECTIVE OF STUDENTS AND FACULTY MEMBERS ON THE EFFICIENCY AND USABILITY OF E-LEARNING COURSES AT AJMAN UNIVERSITY: A CASE STUDY," Journal of Technology and Science Education, vol. 9, no. 3, pp. 388-403, 2019. 